\title{
Use of ICD-10-CM coded hospitalisation and emergency department data for injury surveillance
}

\author{
Renee L Johnson ๑,${ }^{1}$ Holly Hedegaard $\odot,{ }^{2}$ Emilia S Pasalic $\odot, '$ \\ Pedro D Martinez ${ }^{1}$
}

Injury surveillance, the ongoing, systematic collection, analysis, interpretation and dissemination of injury data, provides critical information to support public health efforts to reduce injury-related morbidity, mortality and disability. ${ }^{12}$ For the past several decades, state and local health departments and national agencies in the USA have relied on the use of hospital discharge and emergency department (ED) data coded using the International Classification of Diseases, Ninth Revision, Clinical Modification (ICD-9-CM) to conduct injury surveillance. ${ }^{3}$ Surveillance case definitions and analyses have been based on ICD-9-CM codes. However, a US mandate to code using the International Classification of Diseases, Tenth Revision, Clinical Modification $(\mathrm{ICD}-10-\mathrm{CM})^{45}$ has resulted in a need to update injury surveillance case definitions and analysis guidance based on ICD-10-CM. ${ }^{6-9}$

Beginning in October 2015, the US Department of Health and Human Services required all hospitals and healthcare providers covered by the Health Insurance Portability and Accountability Act to use the ICD-10-CM to report electronic healthcare transactions. ${ }^{45}$ The coding structure of ICD-10-CM is based on ICD-10 mortality coding and classification published by the WHO, however, the classification scheme has been greatly expanded to capture the diagnostic detail needed for medical diagnoses. ICD-10-CM contains nearly five times the number of codes found in ICD-9-CM (approximately 72000 codes in ICD-10-CM compared with 15000 codes in ICD-9-CM). Because ICD-10-CM captures greater detail than either ICD-9-CM or ICD-10, this classification system has the potential to provide

${ }^{1}$ National Center for Injury Prevention and Control, Centers for Disease Control and Prevention, Atlanta, Georgia, USA

${ }^{2}$ National Center for Health Statistics, Centers for Disease Control and Prevention, Hyattsville, Maryland, USA

Correspondence to Ms Renee L Johnson, National Center for Injury Prevention and Control, Centers for Disease Control and Prevention, Atlanta, GA 30329 4018, USA; rej2@cdc.gov enhanced understanding of the types and causes of non-fatal injury.

Epidemiologists and researchers who are transitioning from the use of ICD-9-CM coded data to ICD-10-CM coded data should note the substantial differences in the injury diagnosis and external causeof-injury codes in the two coding systems. These differences, which have the potential to either introduce or alleviate bias in non-fatal injury measurement, have been described in detail elsewhere. ${ }^{10}$ Important differences that have implications for injury surveillance include:

- Changes in the codes that identify events involving poisoning or toxic effects. In ICD-9-CM, two codes were required to describe each poisoning event-a diagnosis code (960-979 and 980-989) to describe the type of drug or toxic substance involved and an external cause code (E850-E858, E860-E869, E930-E949, E950E952, E961-E962 and E980-E982) to describe the intent of the poisoning or adverse effect (eg, accidental (unintentional), intentional selfharm, homicide or undetermined). In ICD-10-CM, the information about both the drug or substance involved and the intent are captured in a single code (T36-T50 for drugs and biological substances, and T51-65 for toxic effects of non-drug substances). These $\mathrm{T}$ codes contain a character in the code to specify the intent of the poisoning (ie, accidental (unintentional), intentional self-harm, assault, undetermined, adverse effect and underdosing).

- Expansion of codes to identify events involving asphyxiation. ICD-10-CM contains more than 40 diagnosis codes for asphyxiation or strangulation by different mechanisms (T71 codes), compared with a single diagnosis code in ICD-9-CM (994.7). The T71 codes include a character in the code to specify the intent (ie, accidental (unintentional), intentional self-harm, assault and undetermined) of the asphyxiation.
- Separate codes in ICD-10-CM (T74 and T76) distinguish between suspected and confirmed child and adult abuse and neglect.

- Introduction of the new concept of encounter type in ICD-10-CM. Most injury diagnosis codes and external cause codes in ICD-10-CM include a seventh character (a letter) that provides information on the type of medical care encounter when the diagnosis or external cause-of-injury was determined. The character specifies whether the injury diagnosis is related to: (1) the initial encounter, defined as while the patient is receiving active treatment for the condition, (2) a subsequent encounter, defined as routine care during the healing or recovery phase after the active treatment phase has ended or (3) sequelae, defined as complications or conditions that arise as a direct result of an injury.

- Consideration of both diagnosis codes and external cause codes to identify all cases of intentional self-harm. In ICD-9-CM, all mechanisms of intentional self-harm were captured using external cause codes. In ICD-10-CM, while many mechanisms of intentional self-harm are captured using external cause codes (X71-X83), intentional self-harm involving poisoning or asphyxiation are captured by diagnosis codes (subsets of T36-T65 and T71). ${ }^{11}$

Collectively, the changes introduced with ICD-10-CM mark a major change in the way that many types and causes of non-fatal injury are measured. For many injury subcategories, like drug overdose and asphyxiation, there is no simple oneto-one crosswalk from ICD-9-CM to ICD-10-CM. As epidemiologists standardise new non-fatal injury surveillance methodologies using ICD-10-CM, we cannot assume that injury trends will be consistent across the transition and we must strive to understand the predictive value, sensitivity and specificity of new injury codes and case definitions.

With increased access to ICD-10-CM coded hospital discharge and ED data, epidemiologists and researchers have begun to explore the nuances and implications of using ICD-10-CM coded data for injury surveillance. To promote standardisation across time and among data sets, the US Centers for Disease Control and Prevention's National Center for Injury Prevention and Control and National Center for Health Statistics have developed or updated basic case definitions and reporting frameworks for use with 
ICD-10-CM coded data. ${ }^{6-9}$ These case definitions and frameworks provide a foundation for general injury surveillance, however, the changes introduced with ICD-10-CM warrant in-depth exploration for each injury subcategory.

This Injury Prevention supplement highlights studies that help clarify methodological considerations when using ICD-10-CM coded data and that provide information to support decision-making for developing surveillance case definitions for subcategories of injuries. The studies cover a spectrum of injury topics including general injury, drug overdose, unintentional falls, intentional self-harm, violence, child abuse and neglect, traumatic brain injury and work-related injury. While this supplement is by no means exhaustive, a broad range of injury topics are explored using a variety of methods. For example, several studies reveal considerations for understanding injury trends and discontinuities across the transition, ${ }^{12} 13$ while other studies used medical chart review to estimate the positive predictive value of ICD-10-CM codes and new standardised case definitions. ${ }^{14} 15$ Each of the studies presented in this supplement provides a glimpse into the challenges and potential of using ICD-10-CM coded data for injury surveillance.

While the focus of this journal supplement is on the analysis of ICD-10-CM coded hospitalisation and ED administrative (billing) data, ICD-10-CM may also be applied to billing data for other types of medical encounters (eg, clinician's office visits, care provided by emergency medical services), as well as syndromic and registry data. Exploration and publication of how ICD-10-CM functions in each additional data source is important for gaining a fuller picture of injury and the impact of the transition to ICD-10-CM coding for injury surveillance.

Acknowledgements The editors thank the individual authors and institutions that helped make this journal supplement a reality. We look forward to seeing how the use of ICD-10-CM coded data will increase the understanding of injury and injury prevention efforts for years to come.

Contributors Each of the four guest editors have contributed to the management of manuscript solicitation, selection and preparation for final acceptance. They have additionally each contributed to the development and writing of the Editorial.

Funding The authors have not declared a specific grant for this research from any funding agency in the public, commercial or not-for-profit sectors.

Disclaimer The findings and conclusions in this report are those of the author(s) and do not necessarily represent the views of the Centers for Disease Control and Prevention.

Competing interests None declared.

Patient and public involvement Patients and/or the public were not involved in the design, or conduct, or reporting, or dissemination plans of this research.

Patient consent for publication Not required.

Provenance and peer review Commissioned; externally peer reviewed.

\section{(2) OPEN ACCESS}

Open access This is an open access article distributed in accordance with the Creative Commons Attribution Non Commercial (CC BY-NC 4.0) license, which permits others to distribute, remix, adapt, build upon this work non-commercially, and license their derivative works on different terms, provided the original work is properly cited, appropriate credit is given, any changes made indicated, and the use is non-commercial. See: http:// creativecommons.org/licenses/by-nc/4.0/.

(c) Author(s) (or their employer(s)) 2021. Re-use permitted under CC BY-NC. No commercial re-use. See rights and permissions. Published by BMJ.

\section{D) Check for updates}

To cite Johnson RL, Hedegaard H, Pasalic ES, et al. Inj Prev 2021;27:i1-i2.

Inj Prev 2021;27:i1-i2.

doi:10.1136/injuryprev-2019-043515

\section{ORCID iDs}

Renee L Johnson http://orcid.org/0000-0002-20301172

Holly Hedegaard http://orcid.org/0000-0002-4235-

0733

Emilia S Pasalic http://orcid.org/0000-0003-3692-3424

\section{REFERENCES}

1 Horan JM, Mallonee S. Injury surveillance. Epidemiol Rev 2003;25:24-42.

2 Sogolow ED, Sleet DA, Saul J. Dissemination, implementation, and widespread use of injury prevention intervention. In: Doll LS, Bonzo SE, Sleet DA, et al, eds. Handbook of injury and violence prevention. New York: Springer, 2007.

3 Safe States Alliance. Consensus recommendations for injury surveillance in state health departments. A report from the Injury Surveillance Workgroup 5 (ISW5). Atlanta, GA; 2007. https://cdn.ymaws.com/ www.safestates.org/resource/resmgr/imported/ general//SW5_Report_Final.pdf
4 Centers for Medicare \& Medicaid Services. International classification of diseases, 10th revision. Baltimore, MD. Available: https://www.cms.gov/ Medicare/Coding/ICD10/index.html?redirect=/icd10/

5 National Center for Health Statistics. International classification of diseases, 10th revision, clinical modification (ICD-10-CM). Hyattsville, MD. Available: https://www.cdc.gov/nchs/icd/icd10cm.htm

6 Hedegaard H, Johnson RL. An updated International classification of diseases, 10th revision, clinical modification (ICD-10-CM) surveillance case definition for injury hospitalizations. National health statistics reports; no 125. Hyattsville, MD, National Center for Health Statistics; 2019. https://www.cdc.gov/nchs/ data/nhsr/nhsr125-508.pdf

7 Hedegaard HB, Johnson RL, Ballesteros MF. Proposed ICD-10-CM surveillance case definitions for injury hospitalizations and emergency department visits. National health statistics reports; no 100. Hyattsville, MD, National Center for Health Statistics; 2017. https://www.cdc.gov/nchs/data/nhsr/NHSR100.pdf

8 Hedegaard H, Johnson RL, Garnett MF. The International classification of diseases, 10th revision, clinical modification (ICD-10-CM) external cause-ofinjury framework for categorizing mechanism and intent of injury. National health statistics reports; no 136. Hyattsville, MD, National Center for Health Statistics; 2019. https://www.cdc.gov/nchs/data/nhsr/ nhsr136-508.pdf

9 Hedegaard H, Johnson RL, Garnett MF. The 2020 International classification of diseases, 10th revision, clinical modification (ICD-10-CM) injury diagnosis framework for categorizing injuries by body region and nature of injury. National health statistics reports; no 150. Hyattsville, MD, National Center for Health Statistics; 2020. https://www.cdc.gov/nchs/data/nhsr/ nhsr150-508.pdf [Accessed December 28, 2020].

10 Safe States Alliance. The transition from ICD-9-CM to ICD-10-CM: guidance for analysis and reporting of injuries by mechanism and intent. A report from the injury surveillance Workgroup 9 (ISW9). Atlanta, GA; 2016. https://cdn.ymaws.com/www.safestates.org/ resource/resmgr/isw9/ISW9_FINAL_Report.pdf

11 Hedegaard H, Schoenbaum M, Claassen C. Issues in developing a surveillance case definition for nonfatal suicide attempt and intentional self-harm using International classification of diseases, 10th revision, clinical modification (ICD-10-CM) coded data. National health statistics reports; no 108. Hyattsville, MD, National Center for Health Statistics; 2018. https:// www. cdc. gov/ nchs/ data/ nhsr/ nhsr108.pdf

12 Moreland BL, Burns ER, Haddad YK. National rates of nonfatal emergency department visits and hospitalizations due to falls in older adults 2010-2014 and 2016, transitioning from ICD-9-CM to ICD-10-CM. Inj Prev 2021;27:i75-8.

13 Yang $H$, Pasalic E, Rock P. Interrupted time series analysis to evaluate the performance of drug overdose morbidity indicators shows discontinuities across the ICD-9-CM to ICD-10-CM transition. Inj Prev 2021;27:i35-41.

14 Gabella BA, Hathaway JE, Hume B. Multi-Site medical record review of emergency department visits for traumatic brain injury. Inj Prev 2021;27:i59-65.

15 Peterson A, Gabella BA, Johnson J. Multi-Site medical record review of emergency department visits for unspecified injury of head following the ICD-10-CM coding transition. Inj Prev 2021;27:i13-18. 